\title{
Sleep problems and social support: Frailty in a Brazilian Elderly Multicenter Study ${ }^{1}$
}

\author{
Shintia Viana da Costa ${ }^{2}$ \\ Maria Filomena Ceolim ${ }^{3}$ \\ Anita Liberalesso $\mathrm{Neri}^{4}$
}

This study identifies relationships among the quality of perceived social support and sleep problems and napping habits in community-dwelling elderly. This study is part of a larger multicenter project entitled "Frailty in Brazilian Elderly Individuals", conducted in 17 Brazilian cities. A total of 498 elderly individuals capable of participating in interviews and free of cognitive deficits or functional impairment were found. The following instruments were used in data collection: Questionnaire addressing socio-demographic data; Interpersonal Support Evaluation List; questions concerning sleep patterns (Nottingham Health Profile); questions related to napping habits (Minnesota Leisure Activity Questionnaire). Descriptive statistics and the Mann-Whitney test were used for data analysis. The elderly individuals who reported having sleep problems in general, taking longer to fall asleep and sleeping poorly at night had lower scores on the Interpersonal Support Evaluation List than the elderly who denied such problems. Strategies to improve the quality of social support could also help reduce sleep problems.

Descriptors: Sleep; Social Support; Aged; Nursing.

\footnotetext{
${ }_{1}$ Paper extracted from undergraduate course conclusion monograph "Problemas do sono e suporte social percebido em idosos residentes na comunidade", presented to Faculdade de Ciências Médicas, Universidade Estadual de Campinas, SP, Brazil.

2 Nursing undergraduate student, Faculdade de Ciências Médicas, Universidade Estadual de Campinas, SP, Brazil. E-mail: shintiaviana@yahoo.com.br.

${ }^{3}$ RN, Ph.D. in Nursing, Associate Professor, Faculdade de Ciências Médicas, Universidade Estadual de Campinas, SP, Brazil. E-mail: fceolim@fcm.unicamp.br.

${ }^{4}$ Psychologist, Full Professor, Faculdade de Educação, Universidade de Campinas, SP, Brazil. E-mail: anitalbn@uol.com.br.
}

Corresponding Author: Maria Filomena Ceolim Unicamp. Faculdade de Ciências Médicas. Departamento de Enfermagem. Rua Tessália Vieira de Camargo, 126 Cidade Universitária "Zeferino Vaz" CEP: 13083-887, Campinas, SP, Brasil E-mail: fceolim@fcm.unicamp.br 


\title{
Problemas de sono e suporte social: estudo multicêntrico Fragilidade em Idosos Brasileiros
}

Esta pesquisa teve como objetivo identificar relações entre qualidade do suporte social percebido, problemas de sono e hábito de cochilar, em idosos da comunidade. Trata-se de recorte do estudo Fragilidade em Idosos Brasileiros (Fibra), projeto multicêntrico, desenvolvido em 17 cidades brasileiras. Participaram 498 idosos, capazes de responder às entrevistas, sem déficit cognitivo ou funcional grave. Adotou-se, para coleta de dados: questionário sociodemográfico, escala de percepção da qualidade do suporte social, questões sobre problemas de sono (perfil de saúde de Nottingham); questões sobre hábito de cochilar (Minnesota Leisure Activity Questionnaire). Utilizou-se estatística descritiva e teste de Mann-Whitney para tratamento dos dados. Idosos que referiram problemas de sono em geral, demorar para adormecer e dormir mal à noite apresentaram escores inferiores aos dos idosos que negavam esses problemas, na escala de percepção de qualidade de suporte social. Estratégias para melhoria da qualidade de suporte social poderiam contribuir para minimizar problemas de sono.

Descritores: Sono; Apoio Social; Idoso; Enfermagem.

\section{Problemas de sueño y soporte social: estudio multicéntrico sobre Fragilidad en Ancianos Brasileños}

\begin{abstract}
Este artículo tiene como objetivo identificar relaciones entre calidad del soporte social percibido, problemas de sueño y hábito de dormitar, en ancianos de la comunidad. Se trata de un recorte del estudio Fragilidad en Ancianos Brasileños (FIBRA), proyecto multicéntrico desarrollado en 17 ciudades brasileñas. Participaron 498 ancianos, capaces de responder a las entrevistas, sin déficit cognitivo o funcional grave. Se adoptó para la recolección de datos: el Cuestionario Sociodemográfico; la Escala de Percepción de la Calidad del Soporte Social; preguntas sobre problemas de sueño (Perfil de Salud de Nottingham); y, preguntas sobre el hábito de dormitar (Minnesota Leisure Activity Questionnaire). Se utilizó estadística descriptiva y prueba de Mann-Whitney para tratamiento de los datos. Los ancianos que refirieron problemas de sueño en general, demorar en adormecer y dormir mal en la noche, presentaron puntajes inferiores a los de ancianos que negaban esos problemas, en la Escala de Percepción de Calidad de Soporte Social. Las estrategias para mejorar la calidad de soporte social podrían contribuir para minimizar los problemas de sueño.
\end{abstract}

Descriptores: Sueño; Apoyo Social; Anciano; Enfermería.

\section{Introduction}

Brazil has a contingent of close to 22 million people older than 60 years of age, a number that exceeds the population of elderly individuals in many European countries. Considering only the segment of people 75 years old or older (about 5.6 million), the elderly population in Brazil has a significant proportion, very different from the age profile that was considered extremely young not so long ago(1).
The aging process usually alters one's habitual sleep pattern. Of these alterations, various ones may correspond to sleep disorders or loss of sleep quality. Among them the following stand out: quantitative decrease in stages of deep sleep; lowered threshold for awakening due to noise, associated with a quantitative increase of superficial sleep; increased sleep onset latency; reduction of nighttime sleep duration; increased 
number of transitions from one stage to another and wakefulness; increased frequency of respiratory disorders during sleep, especially among men; increased nocturnal myoclonic activity ${ }^{(2)}$.

Studies show there is a significant relationship between the influence of social networks and the quality of sleep among elderly individuals. Most elderly individuals who have good family relationships and play a role in society, together with a network of friends, have better performance in relation to quality of sleep ${ }^{(3)}$. This support network, composed of friends and family, as well as material and emotional resources that are available to a person through interpersonal contact, is called social support. The way individuals recognize available social support is known as 'perceived social support' and can affect one's ability to cope with mental and physical health problems ${ }^{(4)}$.

Social support is noted as an important variable in the maintenance of health. Socially active individuals who have more relationships are exposed to strong normative pressure and control from friends and family members to demonstrate healthy behavior and seek health care whenever necessary. Additionally, a social support network contributes to individuals with multiple sources of information, increasing the probability of access to information that promotes healthy behavior and minimizes situations of risk and stress ${ }^{(5)}$.

Even though the main causes of death among elderly individuals are chronic diseases such as myocardial infarction, stroke, diabetes and hypertension, one of the most relevant and also misunderstood factors that can also lead elderly individuals to death is social isolation. The negative consequences of it are particularly relevant in segments of the population that face rapid growth, such as the elderly population ${ }^{(5)}$.

The current literature reports that both a lack of social support and sleep disorders represent risk factors for diseases of both emotional and physical origins. Individuals who feel socially isolated show signs of high vascular activation and fragmented sleep. A recent study showed that socially isolated adult individuals reported poor quality sleep and had increased daytime sleepiness. Given the results suggesting that subjective quality of sleep of solitary individuals is harmed, we highlight that quantitative and qualitative deprivation of sleep generates deficient health and is an important mechanism through which loneliness harms health ${ }^{(6)}$.

A study verified that sleep disorders constitute mediators in the association between a lack of social support and the occurrence of acute myocardial infarction in adult women. This mediation may be related to the stressor role of poor social support that would trigger cognitive and emotional responses to excessive physiological stimuli and, consequently, would trigger sleep disorders ${ }^{(7)}$.

The importance of nurses actively assessing the social conditions of elderly individuals under their care and support the strengthening of relationships with family members, as well as with friends, is highlighted(3).

Sleep disorders are increasingly recognized for their potential to harm the health of elderly individuals; the previous conception that sleep disorders are common and even harmless in old age has been abandoned(8). Hence, the identification of aspects associated with the poor sleep of elderly individuals can enable, in the medium and long term, the delineation of nursing interventions focused on the resolution or minimization of such disorders. Through the analysis of a potential association between reports of frequent sleep problems in old age and the quality of perceived social support, as well as the further association between this and the habit of taking naps, we expect to identify another factor that can be the target of health professionals' assessment and interventions promoting the health of elderly individuals.

Therefore, this study identifies the relationship between quality of perceived social support and sleep disorders and the habit of taking naps among elderly individuals living in the community.

\section{Methods}

This study is part of a larger multicenter, multidisciplinary population study addressing the health conditions and well being of men and women 65 years old or older, entitled "Frailty in Brazilian Elderly Individuals" (the FIBRA Study), conducted by a network composed of researchers from four Brazilian universities. The project is supported by the National Research Council (CNPq).

The FIBRA Study was carried out in 17 Brazilian cities, among them the city of Campinas, SP, for which the sample is composed of 900 elderly individuals, recruited at home, through urban census sectors drawn at random. Recruiters were trained and followed a script for introducing themselves, presenting the study and inviting the elderly individuals to participate in the study according to a previously tested script specifically developed for the study.

Data collection proceeded after the individuals signed free and informed consent forms. The individuals' 
cognitive status was assessed through a screening test, the Mini-Mental State Examination $(\mathrm{MMSE})^{(9)}$. Those scoring above the MMSE cut-off point, considering their educational level, $(n=689)^{(10)}$ participated in all the interviews and evaluations, which resulted in a set of variables. Included in that set were variables of interest to this study.

Inclusion criteria: being 65 years old or older, understanding the instructions, and being a resident in the household and census sector.

Exclusion criteria: a) severe cognitive deficit suggestive of dementia, evidenced by memory and attention problems, spatial and temporal disorientation, and communication problems observed by the recruiters; b) using a wheelchair or being bedridden; c) severe sequelae from stroke with loss of strength and/or aphasia; d) Parkinson's disease in a severe or unstable stage, with severely compromised motor skills, speech or affectivity; e) severe hearing or eyesight impairment that strongly hindered communication; and f) terminal stage.
This study is part of the FIBRA Study and focuses on the relationship between the variables 'perceived social support'; general and specific 'sleep problems'; and 'habit of taking naps'. In addition to these, the following socio-demographic variables were used to characterize the population: gender, age, race, marital status, occupation, schooling, family income, and characteristics of family arrangements and housing.

In addition to the selection criteria observed in the FIBRA Study, this study also observed:

Inclusion criteria: answering all the questions addressing the variables concerning perceived social support, sleep disorders and habit of taking naps; and at least $75 \%$ of the questions addressing sociodemographic data.

Exclusion criteria: contradictorily answering the questions related to sleep, that is, do not report sleep problems in general but indicate specific sleep problems, or either report sleep problems in general but not specific sleep problems.

Figure 1 shows the final composition of the studied sample.

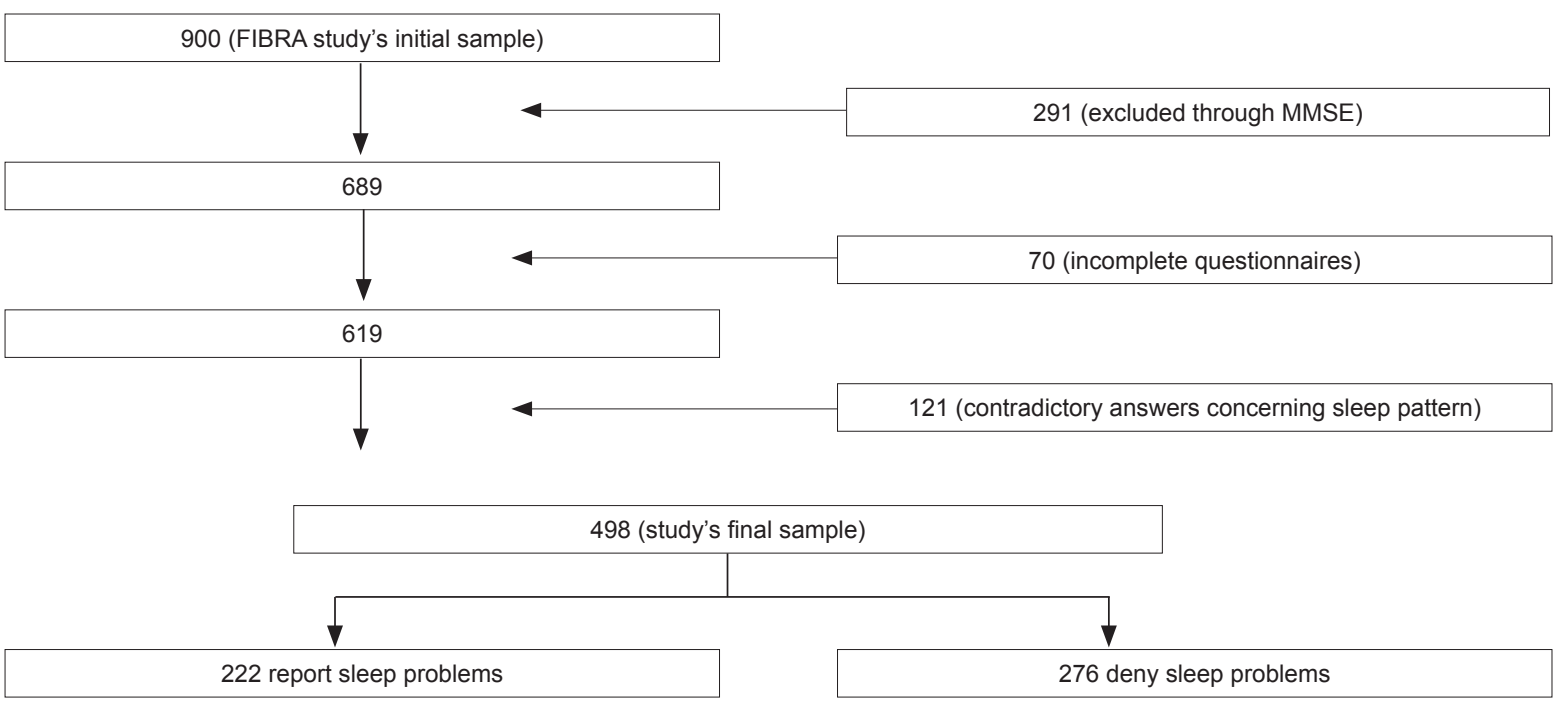

Figure 1 - Flow chart illustrating the final sample composition. Campinas, Brazil 2008-2009

Socio-demographic data were collected through an instrument developed by the researchers from the FIBRA Study. The instrument used for data collection addressing the quality of perceived social support was a short version of the Interpersonal Support Evaluation List (ISEL) with five scaled items having values up to four points ${ }^{(11)}$. It was developed for the general population in order to measure four functions of perceived social support: tangible support (material or instrumental support); belonging (identification with someone in the support network), self-esteem (positive comparisons with others) and evaluative support (informational support). Each item has a scale with the possible answers and scores: (1) never; (2) sometimes; (3) most of the times; (4) always. The maximum possible score in the short version is $20^{(11)}$.

The evaluation of sleep disorders was obtained through six questions addressing sleep patterns from the Nottingham Health Profile validated in Brazil(12). The questions referred to the last 12 months: 1 . Have you 
had sleep problems?; 2. Have you taken sleeping pills? 3. Have you ever awakened during the night and could not return to sleep?; 4. Have you ever stayed up most of the night? 5. Have you ever taken too long to fall asleep? 6. Have you ever slept poorly? The possible answers were 'yes' and 'no'.

The habit of taking naps was evaluated with two questions from the Minnesota Leisure Activity Questionnaire(13-14), adapted for the FIBRA Study: whether the individual had taken a nap in the last 12 months, and if yes, for how long.

This study was submitted to the Research Ethics Committee at the researchers' institution as an addendum to the FIBRA Study for obtaining approval and also to report that the use of data was authorized by the coordinator of the FIBRA Study. Approval was obtained on August $24^{\text {th }} 2010$ through process CEP 208/2007.

Data were analyzed using through the Statistical Package for Social Sciences (SPSS). Descriptive statistics and frequency tables were used, as well as non-parametric tests for inferential statistics, since the distribution of data was not normal according to the Kolmogorov-Smirnov test. The Mann-Whitney test was used to compare scores of the ISEL among elderly individuals who reported sleep problems and those who denied it, as well as those who napped and those who did not in the last 12 months. Spearman's rank correlation was used to evaluate the correlation between scores of the ISEL and the duration of naps in minutes among those who napped. The level of statistical significance was fixed at $5 \%(\alpha=0.05)$.

\section{Results}

Most of the elderly individuals were women $(341 / 68.5 \%)$, aged between 65 and 74 years old (333/66.85), Caucasian (370/74.3\%), married $(261 / 52.5 \%)$ or widowed $(167 / 33.5 \%)$. Among them, 350 (70.3\%) were retired, 165 (33.1\%) were pensioners and $71(14.3 \%)$ still worked. Family income was five times the minimum wage for half of the elderly individuals (288/57.8\%), and above five times the minimum wage for a fifth of them (112/22.5\%). Most of them had completed primary school (265/53.2\%) and a fifth did not go to school (91/18.3\%). A total of 293 $(58.8 \%)$ elderly individuals were the family head. Half of the elderly individuals had between one and three children (257/51.6\%), and most lived with their spouse or with their spouse and children (373/72.9\%); about one fifth of the elderly individuals lived by themselves $(81 / 16.3 \%)$.

Among the $222(44.6 \%)$ elderly individuals who reported sleep problems in general, 162 (32.5\%) reported "waking up during the night and not being able to return to sleep"; 116 (23.5\%), "stayed up most of the night"; 139 (27.9\%), "took too long to fall asleep"; and $146(29.3 \%)$, "slept poorly at night". The use of sleeping pills was reported by 97 elderly individuals (19.5\%), and naps were reported by $302(60.6 \%)$ individuals. A total of $55(11.0 \%)$ individuals reported only one specific sleep problem among the four previously listed while 64 $(12.9 \%)$ individuals reported all four of the problems.

The scores from the ISEL varied from five to 20 points with an average of $17.0(S D=3.4)$, while the median was 18.0 .

A significant association was found between sleep problems and quality of perceived social support, so that elderly individuals who reported sleep problems in general, prolonged sleep onset latency (length of time one takes to fall asleep) and non-restorative sleep (sleep poorly at night) presented lower scores on the ISEL compared to those who denied such problems. No association was found between taking naps and quality of social support.

Table 1 presents the scores of the ISEL given the occurrence of sleep problems and the habit of taking naps in the last 12 months.

Table 1 - Quality of perceived social support due to sleep problems and habit of napping in the last 12 months. FIBRA study. Campinas, SP, Brazil, 2008-2009

\begin{tabular}{|c|c|c|c|c|}
\hline \multirow{2}{*}{ Sleep problems and napping } & \multicolumn{4}{|c|}{ Quality of perceived social support } \\
\hline & $A^{*}$ & $\mathbf{S D}^{\dagger}$ & Med $^{\ddagger}$ & $\mathbf{p}^{\S}$ \\
\hline Had sleep problems & 16.7 & 3.4 & 17 & \multirow{2}{*}{0.007} \\
\hline Did not have sleep problems & 17.3 & 3.4 & 19 & \\
\hline Took sleeping pills & 16.7 & 3.4 & 18 & \multirow{2}{*}{0.17} \\
\hline Did not take sleeping pills & 17.0 & 3.4 & 18 & \\
\hline Woke up during the night and could not return to sleep & 16.7 & 3.4 & 18 & \multirow{2}{*}{0.096} \\
\hline Did not wake up during the night and be unable to return to sleep & 17.0 & 3.4 & 18 & \\
\hline
\end{tabular}


Table 1 - (continuation)

\begin{tabular}{|c|c|c|c|c|}
\hline \multirow{2}{*}{ Sleep problems and napping } & \multicolumn{4}{|c|}{ Quality of perceived social support } \\
\hline & $A^{*}$ & $\mathbf{S D}^{\dagger}$ & Med $^{\ddagger}$ & $p^{\S}$ \\
\hline Stayed awake most of the night & 16.6 & 3.5 & 18 & \multirow{2}{*}{0.15} \\
\hline Did not stay awake most of the night & 17.0 & 3.3 & 18 & \\
\hline Took long to fall asleep & 16.1 & 3.6 & 17 & \multirow{2}{*}{0.000} \\
\hline Did not take long to fall asleep & 17.4 & 3.2 & 19 & \\
\hline Slept poorly at night & 16.6 & 3.2 & 17 & \multirow{2}{*}{0.03} \\
\hline Did not sleep poorly at night & 17.2 & 3.4 & 18 & \\
\hline Took a nap in the last 12 months & 17.0 & 3.4 & 18 & \multirow{2}{*}{0.62} \\
\hline Did not take a nap in the last 12 months & 17.0 & 3.4 & 18 & \\
\hline
\end{tabular}

$\mathrm{A}^{*}$ : average; $\mathrm{SD}^{+}$: standard deviation; Med": median; ${ }^{\S}=\mathrm{p}$ value in the Mann-Whitney test; statistically significant results are in bold

The average duration of naps for those who took naps was 47 minutes $(S D=36)$ with a median of 30 minutes. No significant correlation was found between duration of naps and the final score in the ISEL (Spearman $r=-$ $0.061, p=$ n.s. ).

\section{Discussion}

An expressive percentage (44.6\%) of elderly individuals in this study reported sleep problems in general. Of these, the most frequent were fragmented sleep and waking up during the night and not being able to return to sleep, followed by sleeping poorly at night and increased sleep onset latency. Attention should also be paid to the non-negligible percentage of individuals who reported all four sleep problems. All these correspond to classical findings reported in literature addressing elderly individuals' sleep patterns ${ }^{(2)}$.

Despite the proportion of elderly individuals with sleep problems, the use of sleeping pills was reported by only $19.5 \%$ of the participants. A study conducted in Sweden with elderly individuals residents of longterm care institutions revealed that most of those with sleep problems were medicated with benzodiazepines; nonetheless lengthy treatments caused dependency and side effects such as anxiety and other sleep problems ${ }^{(15)}$. It suggests that the fact some individuals take sleeping pills does not remove the possibility of the onset of new sleep problems, in addition to causing undesirable side effects for health and quality of life.

Daytime naps were reported by $60.6 \%$ of the elderly individuals and more than half napped for more than 30 minutes a day. This fact may indicate insufficient night sleep ${ }^{(16)}$, though those who did not report sleep problems also napped regularly. Similar findings were obtained by a study conducted with healthy elderly individuals(17). The authors argued that satisfaction with sleep may be preserved in elderly individuals despite signs indicating insufficient night sleep such as daytime naps, suggesting adaptive changes in the elderly individuals' perception of quality sleep ${ }^{(17)}$.

Virtually all the individuals perceived good quality social support, differing from a study performed in Rio de Janeiro, Brazil in which elderly women with low income reported offering support to the family in a higher proportion than the support they received from their family(18). It was an exclusively female population and such a fact should be take into account; $85 \%$ of the elderly women had income below one times the minimum wage ${ }^{(18)}$, a characteristic that differs from that of the participants from this study. These aspects help to explain this discrepancy in relation to perceived social support.

Even though, as previously mentioned, the individuals generally considered themselves to have good quality social support, the individuals who denied having sleep problems perceived social support to be significantly better than those who reported such problems. It suggests that good perceived social support is associated with good quality sleep for these individuals.

Analyzing the differences found in the quality of perceived social support among elderly individuals who reported sleep problems in general, as well as increased sleep onset latency and non-restorative sleep, and those who denied such changes, we find a series of reasons predicting that social support is beneficial for individuals' sleep. First, social support can influence sleep through enabling a feeling of belonging and connection or inducing a positive state of mood and health behavior, including maintenance of healthy sleep habits(19). Additionally, having the perception that there is someone to protect you from social isolation and loneliness, factors related to sleep disorders, may be translated into a situation that provides comfort to the elderly individual. Social 
support also helps to maintain consistency in the sleepwake cycle ${ }^{(19)}$. Such observations also help to explain sleep problems in which differences in scores were significant, since prolonged sleep onset latency is more related to external factors than to the changes in sleep patterns expected in old age. Hence, social support can influence sleep by attenuating effects of psychological stress on it ${ }^{(19)}$.

Changes in the circadian timing system are considered a landmark of aging and have been indicated as factors underlying the elderly individuals' poor quality of sleep. We can assume that the rhythms of daily routine work on the synchronization of circadian rhythms are a protective mechanism that helps to maintain quality of sleep. Such rhythms are linked to the regularity of lifestyle as stabilizing influence on the frequency and duration of activities such as feeding, leisure and social $\operatorname{activities}^{(20)}$. Exploring the connections between better quality social support and the regularity of elderly individuals' routines is an interesting line of investigation to understand the relationship between perceived social support and quality of sleep.

Similarly, it is possible to speculate that daytime naps could be considered an item incorporated into elderly individuals' routines, originating from a reorganization of circadian rhythms that promotes the redistribution of sleep over a 24 hour period and not an indication that sleep is insufficient ${ }^{(21)}$. This aspect can help to explain the absence of a significant correlation between duration of napping and perceived social support quality, which would be expected given the remaining differences found for sleep problems.

\section{Final considerations}

Based on the obtained results that indicate a significant association between sleep problems and quality of perceived social support, the importance of nurses developing a broadened view concerning the relevance of social support for elderly individuals and intervene in it in order to improve these individuals' quality of life is highlighted. In this context, primary health care units are spaces very conducive to the work of this class of professional in health promotion. Hence, nurses can help to minimize or prevent sleep problems among elderly individuals. An action toward this objective would be the creation of educational social groups, gaming groups, exercise, dance and other types of groups in order to increase the social networks of these individuals.
This study did not focus on the occurrence of sleep problems or quality of perceived social support given sociodemographic characteristics. However, it is important that the health team be attentive to these factors when caring for an elderly individual, since there is evidence in the literature related to differences between genders and a better or worse perceived social support.

Further studies with a longitudinal and prospective design are recommended to advance the understanding concerning the causal relationships between perceived social support quality and sleep problems, which was not possible and considered a limitation in this study given its cross-sectional and retrospective nature. Additionally, it is relevant that perceived social support should be investigated concerning other aspects that are related to the occurrence of sleep problems, such as psychological wellbeing, depression, stress and physical symptoms, which were not addressed in this study and can be included in future investigations.

\section{Acknowledgments}

Acknowledgements to Conselho Nacional de Desenvolvimento Científico e Tecnológico (CNPq) by financing of Estudo Multicêntrico Fragilidade em Idosos Brasileiros - FIBRA.

\section{References}

1. Instituto Brasileiro de Geografia e Estatística (IBGE). Síntese de Indicadores Sociais: Uma Análise das Condições de Vida da População Brasileira. Estudos e Pesquisas Informação Demográfica e Socioeconômica. Brasil - 2010. [acesso 22 fev 2011]. Disponível em: http://www.ibge.gov.br/home/estatistica/ populacao/condicaodevida/indicadoresminimos/ sinteseindicsociais2010/SIS_2010.pdf

2. Geib LTC, Cataldo A Neto, Wainberg R, Nunes ML. Sono e envelhecimento. Rev Psiquiatr RS. 2003;25(3):453-65.

3. Yao KW, Yu S, Cheng SP, Chen IJ. Relationships Between Personal, Depression and Social Network Factors and Sleep Quality in Community-Dwelling Older Adults. J Nurs Res. 2008;16(2):131-9.

4. Moak ZB, Agrawal A. The association between perceived interpersonal social support and physical and mental health: results from the national epidemiological survey on alcohol and related conditions. J Public Health. 2010;32(2):191-201.

5. Cacioppo JT, Hawkley LC. Social Isolation and Health, with an Emphasis on Underlying Mechanisms. Perspect Biol Med. 2003;46(3):S39-S52. 
6. Hawkley LC, PreacherKJ, Cacioppo JT. Loneliness Impairs Daytime Functioning but Not Sleep Duration. Health Psychol. 2010;29(2):124-9.

7. Nordin M, Knutsson A, Sundbom E. Is Disturbed Sleep a Mediator in the Association between Social Support and Myocardial Infarction? J Health Psychol. 2008;13(1):55-64.

8. Cunha MCB, Zanetti ML, Hass JV. Sleep Quality in Type 2 Diabetics. Rev. Latino-Am. Enfermagem. set-out 2008;16(5):850-5.

9. Folstein M, Folstein S, McHugh P. Mini-Mental State. A practical method for grading the cognitive status of patients for the clinician. J Psychol Res. 1975;12:18998.

10. Brucki SMD, Nitrini R, Caramelli P, Bertolucci PHF, Okamoto IH. Sugestões para o uso do Mini-Exame do Estado Mental no Brasil. Arq Neuropsiquiatr. 2003;61(3B):777-81.

11. Tavares SS. Sintomas depressivos entre idosos: Relações com classe, mobilidade e suporte social percebidos e experiência de eventos estressantes. [Dissertação de mestrado]. Campinas (SP): Faculdade de Educação da Universidade Estadual de Campinas; 2004. $127 \mathrm{p}$.

12. Teixeira-Salmela LF, Magalhães LC, Souza AC, Lima MC, Magalhães RC, Goulart F. Adaptação do Perfil de Saúde de Nottingham: um instrumento simples de avaliação de qualidade de vida. Cad Saúde Pública. 2004;20(4):905-14.

13. Taylor HL, Jacobs DR, Schucker B, Knudsen J, Leon AS, Debacker G. A questionnaire for the assessment of leisure time physical activities. J Chron Dis. 1978;31:741-55.

14. Ainsworth BE, Haskell WL, Whitt MC, Irwin ML, Swartz AM, Strath SJ. Compendium of physical activities: an update of activity codes and MET intensities. Med Sci Sports Exercise. 2000;32(9):498-516.

15. Holmquist IB, Svensson B, Höglund P. Perceived anxiety, depression, and sleeping problems in relation to psychotropic drug use among elderly in assisted-living facilities. Eur J Clin Pharmacol. 2005;61:215-24.

16. Barichello E, Sawada NO, Sonobe HM Zago MMF. Quality of Sleep in Postoperative Surgical Oncologic Patients. Rev. Latino-Am. Enfermagem. $2009 ; 17(4): 481-8$.
17. Zilli I, Ficca G, Salzarulo P. Factors involved in sleep satisfaction in the elderly. Sleep Med. 2009;10(2):233-9.

18. Sousa AI, Silver LD, Griep RH. Apoio social entre idosas de uma localidade de baixa renda no Munícipio do Rio de Janeiro. Acta Paul Enferm. 2010;23(5):625-31. 19. Troxel WM, Buysse DJ, Monk TH, Begley A, Hall M. Does social support differentially affect sleep in older adults with versus without insomnia? J Psychosom Res. 2010;69:459-66.

20. Zisberg A, Yaish NG, Shochat, T. Contribution of Routine to Sleep Quality in Community Elderly. Sleep. 2010;33(4):509-14.

21. Ceolim MF, Menna-Barreto, L. Sleep/wake cycle and physical activity in healthy elderly people. Sleep Res Online. 2000;3(3):87-95.
Received: Dec. 21 2010 Accepted: May $2^{\text {sd }} 2011$ 